\title{
Diagnosis and Assessment of Deep Pile Cap Foundation of a Tall Building Affected by Internal Expansion Reactions
}

\author{
Fernando A. N. Silva ${ }^{1}{ }^{\circledR}$, João M. P. Q. Delgado ${ }^{2, *}{ }^{\circledR}$, António C. Azevedo ${ }^{2}{ }^{(0}$, Tahlaiti Mahfoud ${ }^{3}$, \\ Abdelhafid Khelidj ${ }^{3}$, Nicole Nascimento ${ }^{1}$ (I) and António G. B. Lima ${ }^{4}$ \\ 1 Departamento de Engenharia Civil, Universidade Católica de Pernambuco, Pernambuco 50050-900, Brazil; \\ fernando.nogueira@unicap.br (F.A.N.S.); nicolenascimentoeng@gmail.com (N.N.) \\ 2 CONSTRUCT, Departamento de Engenharia Civil, Universidade do Porto, Rua Dr. Roberto Frias, $\mathrm{s} / \mathrm{n}$, \\ 4200-465 Porto, Portugal; antonio.costaazevedo@fe.up.pt \\ 3 GeM Laboratory, University of Nantes, Saint Nazaire, 44035 Nantes, France; mahfoud.tahlaiti@icam.fr (T.M.); \\ abdelhafid.khelidj@univ-nantes.fr (A.K.) \\ 4 Department of Mechanical Engineering, Federal University of Campina Grande, \\ Campina Grande 58429-900, Brazil; antonio.gilson@ufcg.edu.br \\ * Correspondence: jdelgado@fe.up.pt; Tel.: +351-225-081-404
}

check for

updates

Citation: Silva, F.A.N.; Delgado, J.M.P.Q.; Azevedo, A.C.; Mahfoud, T.; Khelidj, A.; Nascimento, N.; Lima, A.G.B. Diagnosis and Assessment of Deep Pile Cap Foundation of a Tall Building Affected by Internal Expansion Reactions. Buildings 2021, 11, 104. https://doi.org/10.3390/ buildings11030104

Academic Editor: Carlos Chastre

Received: 3 February 2021

Accepted: 4 March 2021

Published: 9 March 2021

Publisher's Note: MDPI stays neutral with regard to jurisdictional claims in published maps and institutional affiliations.

Copyright: (C) 2021 by the authors Licensee MDPI, Basel, Switzerland. This article is an open access article distributed under the terms and conditions of the Creative Commons Attribution (CC BY) license (https:// creativecommons.org/licenses/by/ $4.0 /)$.
Abstract: Early deterioration of reinforced concrete foundations has been often reported in recent years. This process is usually characterized by an extensive mapping cracking process on concrete surfaces that results from several types of Internal Swelling Reaction (ISR). In this paper, a real case study of a tall reinforced concrete building with a severe deterioration process installed in its deep foundations is discussed. Laboratory tests were performed in concrete drilled cores extracted from a deep pile cap block 19 years after the beginning of construction. Tests to assess the compressive strength, the static and the dynamic modulus of elasticity, the gas permeability, and electron microscopy scanning to find out the primary mechanism responsible for the deterioration observed during in situ inspections. Chemical alterations of materials were observed in concrete cores, mainly due to Delayed Ettringite Formation (DEF), which significantly affected the integrity and durability of the structure. Dynamic modulus of elasticity showed to be a better indicator of damage induced by ISR in concrete than compressive strength. Procedures to strengthen the deteriorated elements using prestressing proved to be an efficient strategy to recover the structural integrity of pile caps deteriorated due to expansions due to ISR.

Keywords: delayed ettringite formation; alkali-aggregate reaction; diagnosis of pathologies on concrete; internal swelling reactions; effect of high temperature during hydration

\section{Introduction}

Early deterioration of foundations of reinforced concrete buildings has been frequently reported in recent years and the installed cracking process is often attributed to concrete internal expansions due to several internal swelling mechanisms [1,2]. This pathology can severely affect the durability of concrete structures and has evolved into an issue of interest not only for researchers but also for the worldwide building industry sector. In this context, the study of the mechanisms that produce concrete deterioration by internal swelling reactions, its effects on the behavior of the material, as well as the investigation of appropriate retrofitting procedures is a field open to research. This paper describes and discusses a diagnosis work performed to identify the origins of an extensive cracking process installed in all the foundation elements of a twenty-year-old, 40-storey residential building. Visual inspections as well as the extraction of concrete drilled cores from the pile caps were performed. Laboratory tests were performed to determine the morphology of the observed pathology, to allow the definition of an adequate rehabilitation solution.

Internal swelling reactions in concrete are often related to pathological manifestations associated with chemical phenomena, most likely present in large concrete volume casting. 
Delayed ettringite formation (DEF) is the most common chemical reaction that includes the formation of expansive products [3]. Some hypotheses have been proposed to explain the origin of delayed ettringite formation [4] and most of them state that the origin of the sulfate ions needed to start DEF comes from the release of hydration products or comes from its deposition in the existing microcracks that can through expansion or growth of ettringite crystals. Regardless of the origin of the internal expansion reactions, it is a consensus among researchers that the occurrence of an intense cracking process contributes to increasing the permeability of the concrete, a fact that compromises its durability $[4,5]$.

A consistent understanding of the expansion mechanisms in concrete generated by the DEF is relevant to the durability of concrete structures. In fact, the DEF expansions can severely affect concrete mechanical characteristics and its global mechanical behavior that often demands a large amount of money to perform retrofitting or rehabilitation works. Another chemical reaction that can generate internal swelling reactions (ISR) in concrete is the alkali silica reaction (ASR), which can also affect the durability of the concrete, because it generates a similar cracking process like those generated by DEF.

Expansion due to ASR also leads to an important cracking process that may impose modifications in structural performance of concrete with influence over its mechanical properties in both service and ultimate load states [5-7].

The chemical process of ASR starts when the silica structure is dissolved by a nucleophilic attack of hydroxide ion $\left(\mathrm{OH}^{-}\right)$, which occurs due to its highly degraded structure behaving like a hygroscopic silica gel. The product that results from this process is a gel known as alkali-silica gel, which is not harmful to concrete [6,7]. However, this gel tends to swell when it absorbs moisture present in the concrete pore solution and, if it is confined in the matrix, it can generate internal stresses. The more the gel absorbs moisture the more the internal pressure increases, inducing, thus, the development of microcracks. In extreme situations, this process can lead to concrete rupture [5-8]. The characteristic pattern and extension of the cracking process provide information about the mechanism of internal expansion reactions and about the magnitude of the microscopic damage to the concrete structure, as explained in [3,5]. Many concrete design codes establish tests to assess the potential reactivity of aggregates used in concrete production with a focus on mortar or concrete specimens [8-10]. However, the great challenge to be overcome in the use of these methods is the reliability of the results provided and their ability to reproduce real situations found in the daily practice of constructing concrete structures $[7,9]$.

Previous researches have already shown that the occurrence of ASR and DEF in concrete structures is a key factor in decreasing the material's characteristics [11-14]. A comprehensive understanding of the damage in concrete structures due to the combination of DEF and ASR effects is presented by Sanchez et al. $[3,5,9,14,15]$. The authors reported ranges of variation in the mechanical properties of concrete related to the level of expansion induced in the investigated specimens.

The existence of a source of moisture, the use of coarse or fine reactive aggregates and a source of alkalis hydroxides are the necessary and sufficient conditions for the occurrence of internal swelling reaction in concrete. This scenario is usually found in cities with ground water levels close to sea level that creates a constant interaction between the moisture and the concrete foundation elements. In such situations, when the cement used to produce the concrete has a high alkalis content and potentially reactive aggregates were also used, the ideal condition to the developed of internal expansions in concrete are created. Damage to concrete structures due to internal expansions presents some signs that indicate its occurrence such as a mapping cracking process, spalling, and disintegration of the cement paste and gel exudation [7-11]. This research intends to understand the effect of concrete internal swelling reaction on the performance of this material under normal load conditions.

In the region where the research was performed, most of the coarse aggregates used in construction of concrete structures is not chemically stable. This happens because the main source of coarse aggregates used in the region come from a zone with tectonic movements 
that generated geological faults. In this region, tensioned, deformed, microgranular, and recrystallized quartz is widely found. From the mineralogical point of view, the deformation observed in the coarse aggregate create ideal conditions for the occurrence of alkali-silicate type expansive reactions.

\section{Experimental Campaign}

\subsection{Visual Inspection}

Visual inspection is one of the initial strategies used to investigate structural behavior of concrete structures. This inspection aims to discover signs of deterioration and the occurrence of pathologies that can affect the durability and load capacity of reinforced concrete structures. The type of visual inspection performed is dependent on the class of information needed, i.e., information to identify construction procedures to produce "as built" documents and drawings, information to identify pathologies in elements, and inspection to extract drilled core samples for further physical and chemical investigations. In the case studied, pile caps of a residential reinforced concrete building were inspected and mapped. Figure 1 shows the situation observed during the visual inspection. The construction is a 45-storey building with a total height of approximately $120 \mathrm{~m}$, which presented the first deterioration signs of its foundations after the very first five years of its construction.

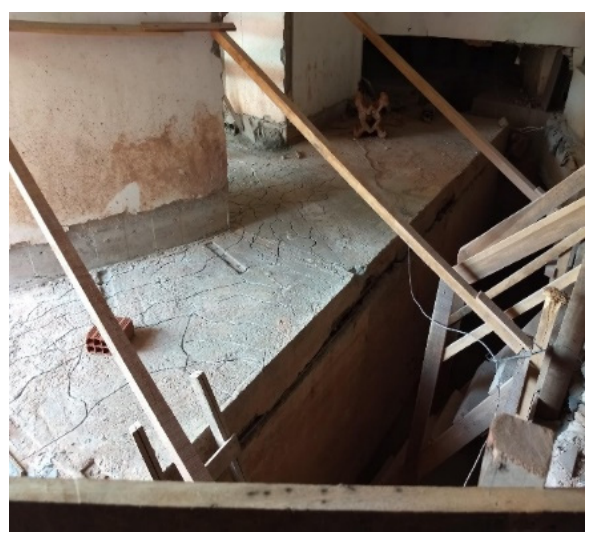

(a)

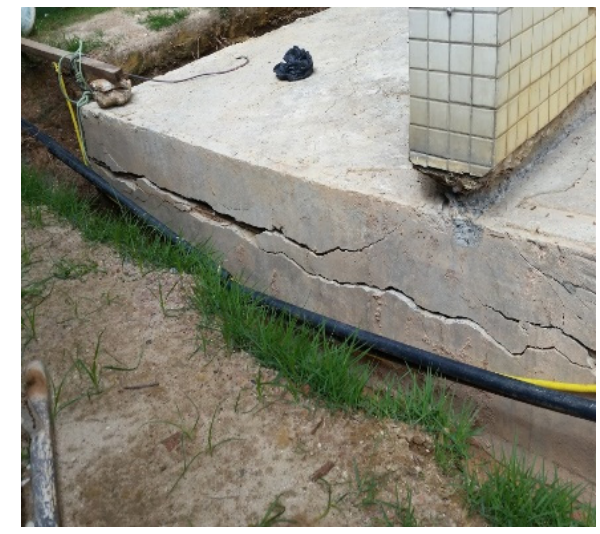

(b)

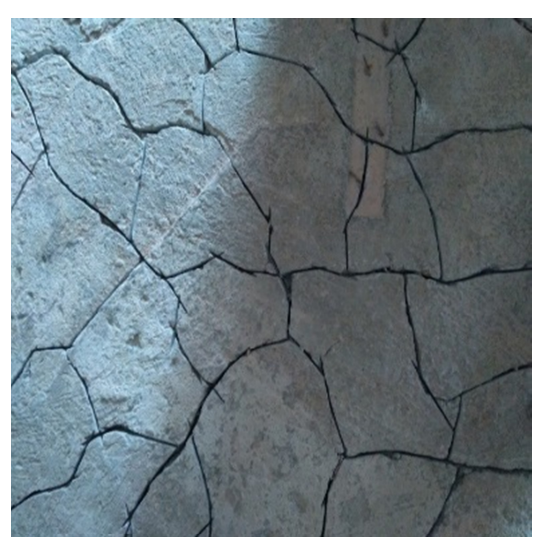

(c)

Figure 1. Cracking process found in the pile caps investigated: (a) Horizontal and map cracking, (b) Large opening longitudinal crack and (c) Map cracking on the surface.

\subsection{Drilled Concrete Cores Extraction}

To assess damage in concrete elements, crack patterns obtained during visual inspection is not enough to get an accurate diagnosis. The extraction of cores close to the surface where mapping cracking occurs is necessary to establish the link between field observations and lab predictions. Table 1 presents data about the drilled concrete cores extracted, the direction of extraction and the lab test that were performed for each sample.

Visual inspections of the drilled concrete cores extracted indicated the existence of cracks in the cement hardened paste, in the transition zone and cracks passing through the coarse aggregate grains, as it is shown in Figure 2. Figure 3 exhibits the places where the alkali-calcium-silica gel was found. These observations are consistent with a scenario generated by pathologies associated with DEF and ASR expansions. 
Table 1. Drilled concrete cores information.

\begin{tabular}{|c|c|c|}
\hline Samples & Extraction Direction & Tests \\
\hline $\mathrm{A}, \mathrm{B}, \mathrm{C}$, and D & Parallel to launch & Point A-Gas Permeability (P-01) \\
\hline SP-01 & Parallel to launch & Gas Permeability (P-02) \\
\hline SP-02 & Parallel to launch & - \\
\hline SP-03 & Parallel to launch & $\begin{array}{l}\text { Static and Dynamic Modulus; Compressive Strength } \\
\text { (AM-02) }\end{array}$ \\
\hline SP-04 & Parallel to launch & - \\
\hline SP-05 & Parallel to launch & $\begin{array}{l}\text { Static and Dynamic Modulus, Compressive Strength } \\
\text { (AM-1A and AM-1B) }\end{array}$ \\
\hline SP-06 & Orthogonal to launch & - \\
\hline
\end{tabular}

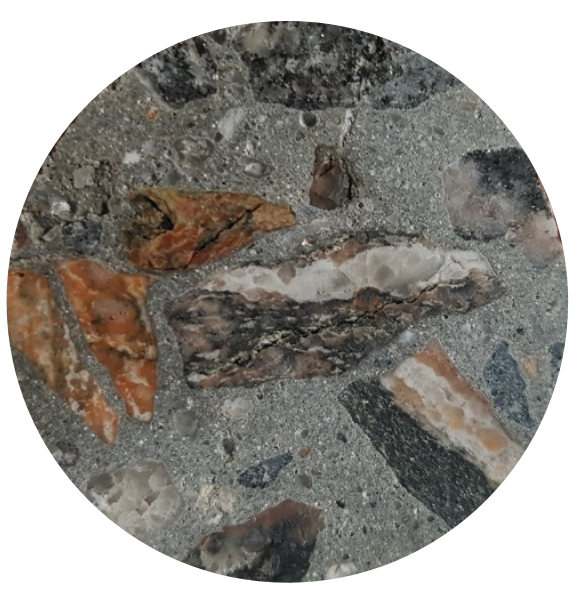

(a)

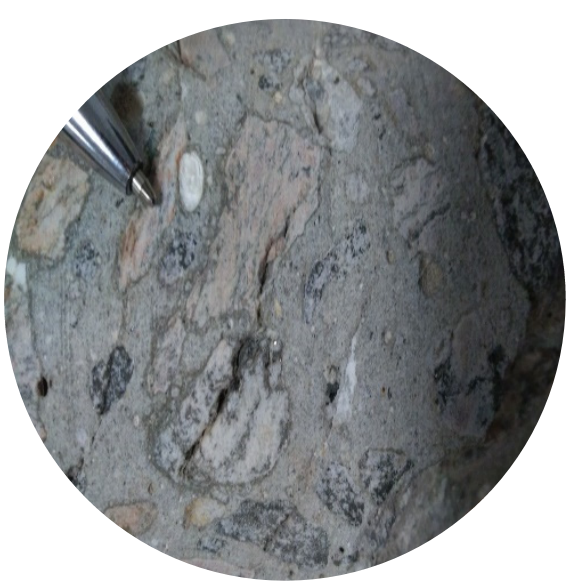

(b)

Figure 2. Cracks found in drilled concrete cores extracted: (a) Cracks passing through coarse aggregates and cracks in the transition zone, (b) Cracks passing through coarse aggregates and cement paste.

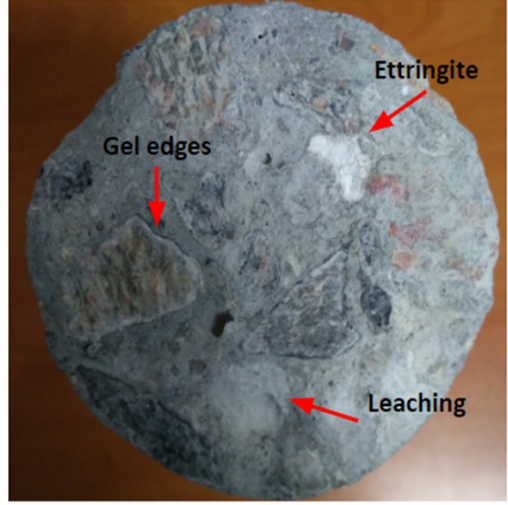

(a)

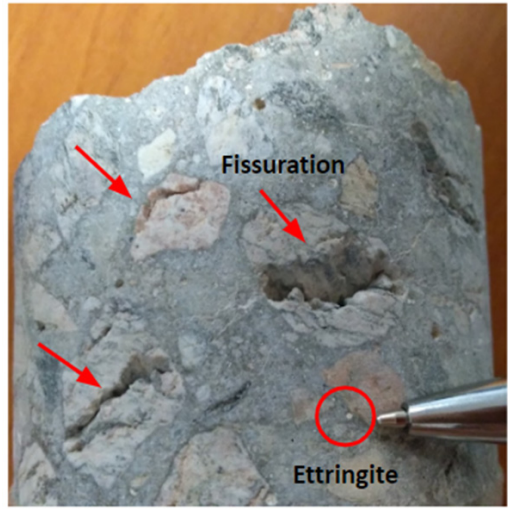

(b)

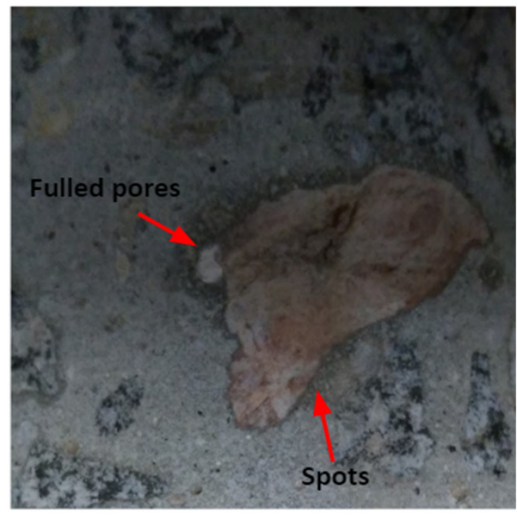

(c)

Figure 3. Symptoms of the expansion mechanisms found: (a) Gel edges; (b) Ettringite in the micropores and cracking; (c) Spots in the aggregate.

\subsection{Laboratory Tests and Analysis}

\subsubsection{Uniaxial Compression Tests}

Generally, the term concrete strength is taken to refer to the uniaxial compressive strength as measured by a short-time compression test of a standard test cylinder. This test if often used to monitor the concrete strength for quality control or acceptance pur- 
poses by designers and engineers and other strength parameters, such as tensile or bond strength, are expressed relative to the compressive strength [16]. In fact, in concrete design the compressive strength is considered to be the material's principal quality parameter used to verify its compliance with standards defined by concrete design code rules. This occurs because compression tests are relatively simple to perform, and their cost is not prohibitive when compared to other tests available to assess other material properties [16]. Many factors affect compressive tests results, such as aggregate type and its reactivity, water-cement ratio $(w / c)$, test age, molding process, curing, micro cracks, porosity, and permeability, among others.

Concrete compressive strength is affected when the material is deteriorated due to ISR. Previous researches have already reported on the ways in which these reactions can directly impact the concrete properties, acting alone or in combination with others ISRs [3,5,9,15-17]. According to Kubo and Nakata ([18], apud 3), the concrete compressive strength is not markedly affected by the internal expansion reactions from ASR, even for high levels of expansion, i.e., $0.30 \%$. When the concrete is deteriorated by DEF combined with ASR or only by DEF expansions, the authors reported loss of compressive strength is not so significant showing values within the range $0.29 \%$ to $0.43 \%$. On the other hand, when the ISRs are due to ASR only, the loss of compressive strength is more pronounced and could reach values around 20 to $35 \%$, for high expansion levels [3].

Three drilled concrete cores were identified and prepared for compression tests (see Figure 4). The ends of core specimens were prepared so as to have a flat surface, perpendicular to the longitudinal axis. Sawing was made prior to capping and it was performed to meet the following requirements: (a) projections, if any, are not to extend more than $5 \mathrm{~mm}$ above the end surfaces; and (b) the end surfaces shall not depart from perpendicularity to the longitudinal axis by a slope of more than $1.8 \mathrm{~d}$ or $1: 0.3 \mathrm{~d}$, where $\mathrm{d}$ is the average core diameter. Capping of concrete cores was performed to assure level and perpendicularity requirements.

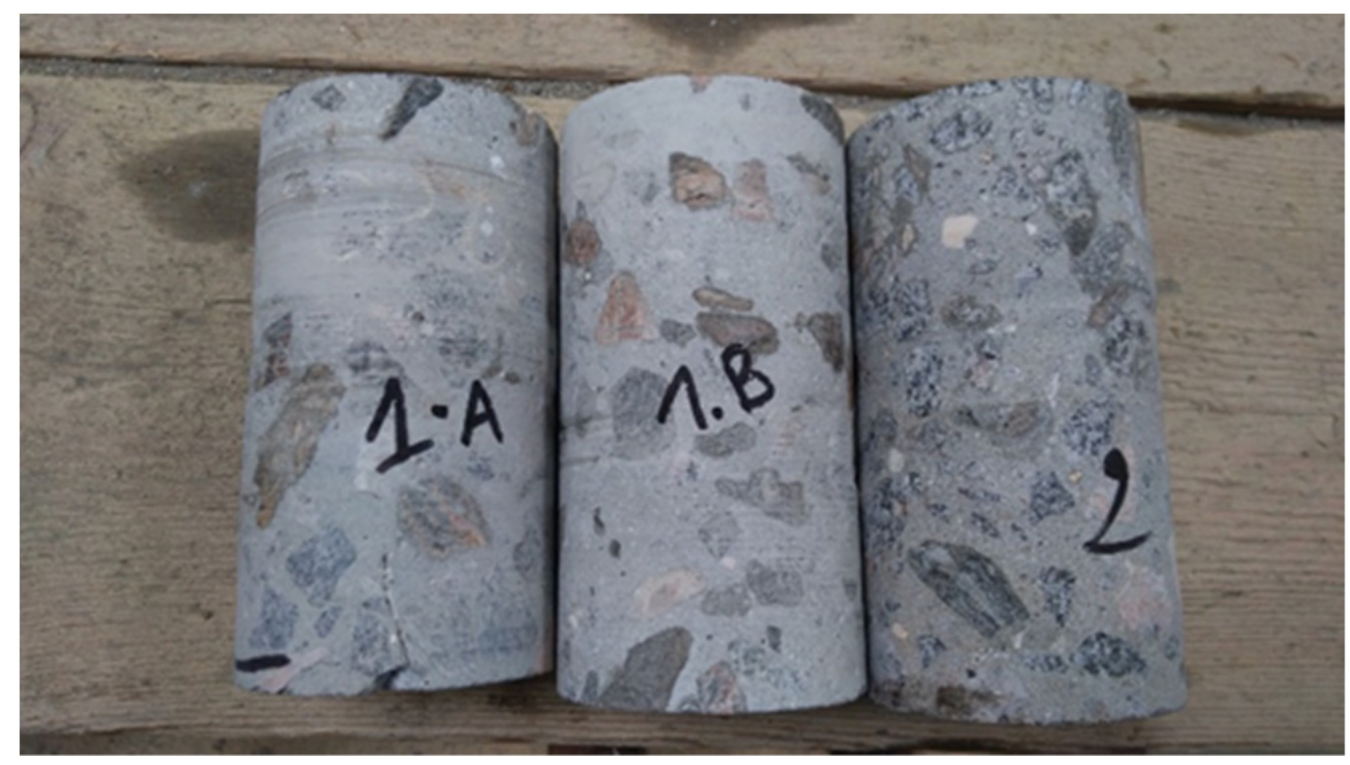

Figure 4. Drilled concrete cores extracted from the pile cap investigated.

Compression strength tests were performed at the GeM Laboratory, University of Nantes, Saint Nazaire, France, using a servo hydraulic compression test machine RP3000 DC/LC (3R-Recherches \& Realisations Remy, Montauban, France) with a maximum load capacity of $2500 \mathrm{kN}$. 


\subsubsection{Static Modulus of Elasticity Tests}

The static modulus of elasticity of a material under tension or compression was calculated using the slope of the stress-strain curve of the concrete under axial loading. Once the behavior of concrete under axial compression is markedly non-linear, three types of static elastic modulus of concrete can be calculated: secant modulus, tangent modulus, and chord modulus. The differences among these three possibilities lies in the way the slope of stress-strain curve from compression tests is calculated [16]. Tangent static modulus of elasticity was calculated because it is a property also used by designers and engineers to verify the quality of concrete to remove concrete shoring, for example.

The elastic characteristics of a material contribute to the definition of its stiffness which is also dependent on the degree of hydration and on the maturity of the concrete. As the drilled concrete cores came from a strongly-loaded deep pile cap, micro-cracks are probably present in the interfacial transition zone (ITZ) around the aggregates. Cracks in the ITZ remain stable until the load applied reaches $30 \%$ of the maximum load. In this stage, stresses and strains are proportional and the $\sigma-\varepsilon$ curve is linear. This way, the static modulus of elasticity can be calculated as the slope of a straight-line tangent to the curve $\sigma-\varepsilon$ at any point on that curve [19]. Previous researches have already reported that static modulus of elasticity of concrete is more sensitive to the effects of the internal expansion reactions than its compressive strength $[3,5,9,13-15,17]$.

The occurrence of DEF expansions alone or combined with ASR expansions in concrete can generate loss of material stiffness in a range between $50 \%$ and $65 \%$. When only DEF expansion is present, the decrease in the values of static modulus of elasticity can reach $67 \%$ [3]. Reactive aggregates contribute to concrete expansion processes generated by DEF and ASR [20].

\subsubsection{Dynamic Modulus of Elasticity Tests}

Dynamic modulus of elasticity of concrete is a parameter often used to assess the degradation and durability of the material. Previous research has reported that dynamic modulus of elasticity of concrete is often higher than the static modulus of elasticity-about 20,30 , and $40 \%$ for high, medium, and low compressive strength concrete, respectively [19].

The usual way to measure the dynamic modulus of elasticity is through an electroacoustic transducer installed on a concrete surface that produces longitudinal vibrations along the length of the element studied. Small stresses are applied during the test and, this way, no micro-cracking is imposed to the tested element. The dynamic modulus of concrete is often associated with purely elastic phenomena and is, in fact, a good parameter to assess material integrity.

Many standards describe methods to calculate the dynamic elastic moduli of concrete samples using impulse excitation technique [21-23]. This procedure has been widely used to assess concrete quality and durability parameters because, among its many advantages regarding the static tests, it provides more precise results due to the lower number of variables involved as well as it makes easier the evolution of damage in the specimens tested. Cracks decrease concrete rigidity, and this decrease reduces the natural frequency of vibration of the material [24].

The procedure comprises the acquisition of the dynamic modulus by measuring the fundamental resonance frequency of a specimen after it has been excited by a light mechanical impulse. This excitation is given in such a way that the desired vibration mode-flexural, torsional, or longitudinal vibration is created in the tested specimen. In the test, the vibration probe was placed at one end of the specimen and the other end received a pulse with the impactor. The frequency was, then, automatically generated 
in the apparatus, and subsequently the dynamic modulus was calculated, based on the code [22]. Equation (1) was used to obtain the dynamic modulus of the concrete:

$$
E d=\frac{0.0016067 L^{3} m\left(1+\frac{5.173484 D^{2}}{L^{2}}-\frac{0.4883 D^{2}}{L^{4}}-\frac{5.28853 D^{4}}{L^{4}\left(1+\frac{5.160942 D^{2}}{L^{2}}\right)}\right) F^{2}}{D^{4}}
$$

where $E d$ is the dynamic modulus of elasticity (GPa), $m$ is the mass of the specimen being tested $(\mathrm{g}), L$ is the length of the specimen being tested $(\mathrm{mm}), D$ is the diameter of specimen being tested $(\mathrm{mm}), F$ is the pulse frequency $(\mathrm{kHz})$. According to ASTM C215 [22], with $v=0.2$ the dynamic modulus was obtained.

The dynamic modulus of elasticity test was used to evaluate the degradation of the drilled concrete cores extracted. The tests were performed at GeM Laboratory, University of Nantes, Saint Nazaire, France, and the equipment adopted was the Grindosonic, J.W. Lemmens-Mk5 Industrial (Grindosonic, Leuven, Belgium).

\subsubsection{Gas Permeability Tests}

Permeability is a property that governs the rate of flow of a gas under pressure through the pore structure of a solid object [19]. This property is useful to evaluate durability characteristics of concrete and is often performed measuring the gas permeability of nonstressed, undamaged concrete specimens $[25,26]$.

Picandet et al. [27] stated that the study of transfer properties of cracked concrete is of paramount importance in predicting its durability, because the leaching and freezing processes depend on the flow of aggressive agents throughout the porous material. Mechanisms such as ASR and DEF also depend on the flow of liquids or gases in the generated microstructure. The cracking process usually produces voids inside the materials, increasing its porosity and modifying its pore structure. Micro-cracks are interconnected until they become macro-cracks creating an interconnectivity that opens ways for the transport of aggressive agents into the element, compromising durability [26,28,29]. Picandet et al. [27] used the overall gas flow to control the cracking pattern in deteriorated concrete samples reporting a good performance from the procedure.

As a hardened concrete element is a thin, porous body, the percolation of gas through its structure can occur through viscous and slipping modes of flow, being the latter also referred as Knudsen's flow [27]. To determine the non-viscous flow the approach proposed by Klinkenberg was used, where an intrinsic permeability coefficient $\mathrm{k}_{\mathrm{v}}\left(\mathrm{m}^{2}\right)$ is associated to the viscous flow [30].

Modifications in the permeability values of a material can be related to an evolution microcracking process. This way, this parameter can indicate the level of damage imposed to a concrete element $[25,31]$. Tahlaiti reported that the porosity of cement-based materials is strongly linked to their transfer properties [32].

Permeability tests were performed on two concrete drilled cores of the pile cap under investigation. Samples with $5 \mathrm{~cm}$ of height and a diameter of $7 \mathrm{~cm}$ were prepared from the extracted core fragments. As the permeability test cell had a diameter of $10 \mathrm{~cm}$, it was necessary to fill the empty space with silicone resin. This resin also had the function of waterproofing the lateral surface of the samples. Figure 5 shows an overview of the properly prepared cores, before testing.

The specimens were dried in an oven for mass stabilization before measuring its dry mass. It should be mentioned that the temperature used to dry the specimens was less than $50{ }^{\circ} \mathrm{C}$. This was done because higher temperatures can lead to destabilized ettringite, modifying, this way, the concrete samples microstructure, particularly when concrete is affected by DEF. Daily measurements of the specimens' mass were performed during 12 days until the variation between the $i$ and $i+1$ measurement was within a specified tolerance. 
The scheme of the permeability equipment used was those reported by [27]. Nitrogen was the neutral percolating gas used and laboratory temperature and relative humidity were controlled and kept constant during the tests- $\mathrm{T}=17.8^{\circ} \mathrm{C}$ and $\mathrm{RH}=76 \%$.

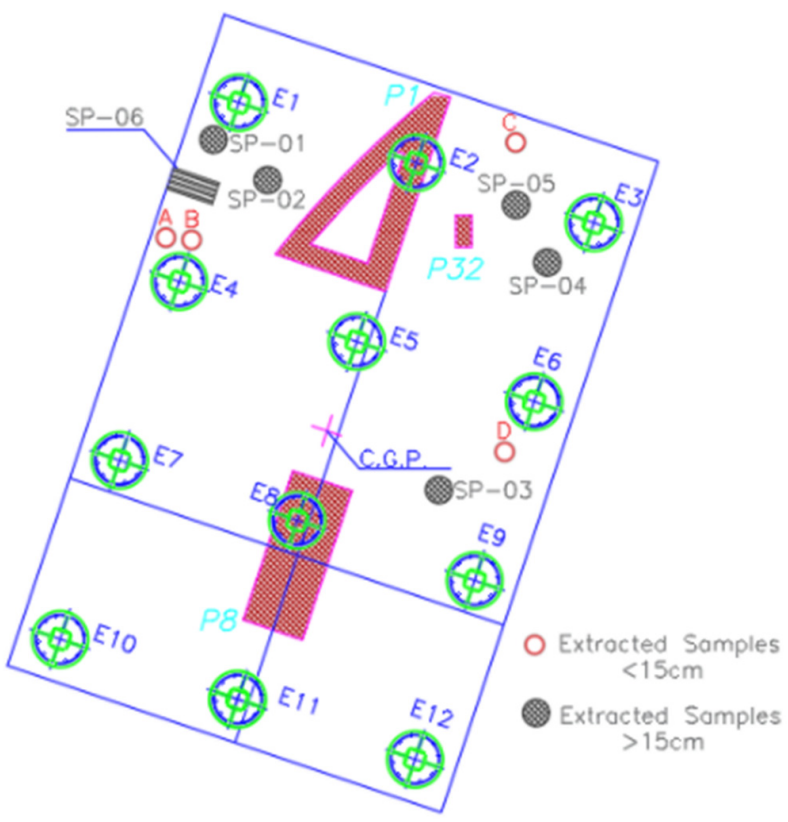

(a)

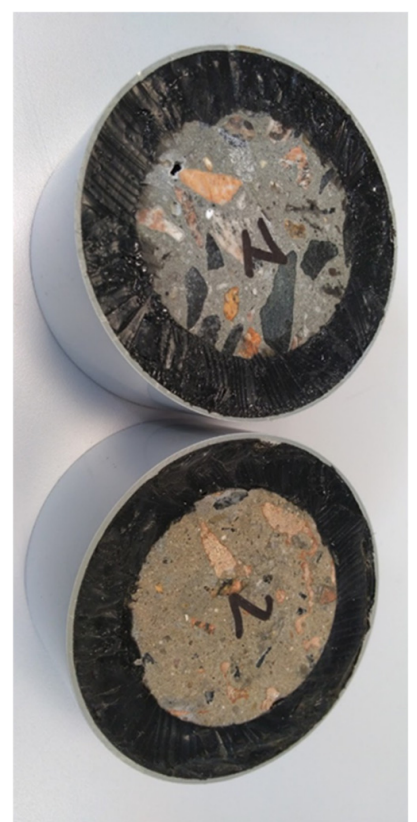

(b)

Figure 5. (a) Extracted samples in pile cap investigated, and (b) Samples P-01 and P-02 prepared for the gas permeability test.

\subsubsection{Scanning Electron Microscopy (SEM) Tests}

The scanning electron microscopy technique is often used for the analysis of damaged concrete because it provides qualified information about the material microstructure. Primary and secondary mineral phases in pores or cracks, morphology, chemical composition can be obtained with such technique. Previous researches performed in concrete affected by ASR have already reported the presence of calcite, quartz, and feldspar minerals in the veins of aggregates that triggered the reaction [33].

Leemann [33] investigated concrete drilled cores extracted from two concrete structures-a bridge built in 1969 and a retaining wall built in 1980-and SEM analysis was used to characterize the microstructure. Cracks in the aggregates filled with ASR products, as well as some fragments of calcite incorporated to the crystalline ASR products were found in the concrete cores.

ZEISS $\mathrm{VVO}^{\circledR} 40$ (Carl Zeiss AG, Oberkochen, Germany) equipped with a Back-scattered Electron (BSE) detector was used to determine the chemical composition of the concrete cores. The microscopic characterizations were performed on fresh fractured sections on concrete specimens. The specimens were coated with a gold deposit for observation using the SEM in High-Vacuum (HV) mode.

\section{Results and Discussion}

\subsection{Summary of ISR in Concrete Cores Compressive Strength}

Three drilled concrete cores with $14.1 \mathrm{~cm}$ of height and $7.45 \mathrm{~cm}$ of diameter of were tested and the results obtained were $47.9 \mathrm{MPa}, 46.76 \mathrm{MPa}$ and $43 \mathrm{MPa}$-average compressive strength was $46 \mathrm{MPa}$. When this result is compared with that expected from the evolution of these properties with time, according to prescriptions of several concrete design codes (44.13 MPa), one can conclude that the ISR did not affect the compressive strength of the concrete. This observation is consistent with previous research $[13,24,34]$ and can be explained by the so-called stopping mechanism of the expansion caused by the 
aggregates [3]. This observation confirms the conclusions of several studies that state that compressive strength is not a good indicator for evaluating the ISR effects on concrete [35]. In the opposite direction, some researchers have reported a great impact generated by ISR on the compressive strength of concrete [36-38]. A possible reason for this divergence may be associated with the time difference in which the two tests were performed. In fact, compressive strength tests were performed by [36,37] after a period of 430 days of the concrete exposure to an environment favourable to DEF development, and the tests reported in this paper were performed 19 years after the construction of the investigated deep pile cap.

Furthermore, it is important to highlight that several authors have already reported that the effects of ISR over concrete mechanical properties is not a closed question with definitive answers, and apparently contradictory results are reported. However, far from being divergent, these results can be explained by the fact that the material response of concrete to ISR is very dependent on the type and nature of the reactive aggregates used $[39,40]$.

\subsection{Summary of ISR in Concrete Cores Static Modulus of Elasticity}

The force-displacement values presented in Figure 6 were converted into stress-strain data to compute elastic modulus using the drilled concrete cores with the same size as those used for compression tests. Three values of the static elastic modulus were obtained for samples AM-1A (19.31 GPa), AM-1B (12.44 GPa), and AM-02 (18.40 GPa) and the average was $16.72 \mathrm{GPa}$. This value is quite distant from the expected ones calculated taking into account the time evolution of static elastic modulus of concrete usually prescribed in concrete design codes (37.20 MPa). The results obtained represent a decrease of approximately $55 \%$ in the static elastic modulus of the concrete, which is consistent with previous research that reported decreases in static elastic modulus of concrete within the range of $50 \%$ to $65 \%$, for moderate expansion levels $(0.30 \%$ to $0.40 \%)$ and decreases close to $85 \%$ for high expansion level, $1 \%[35,37,38]$.

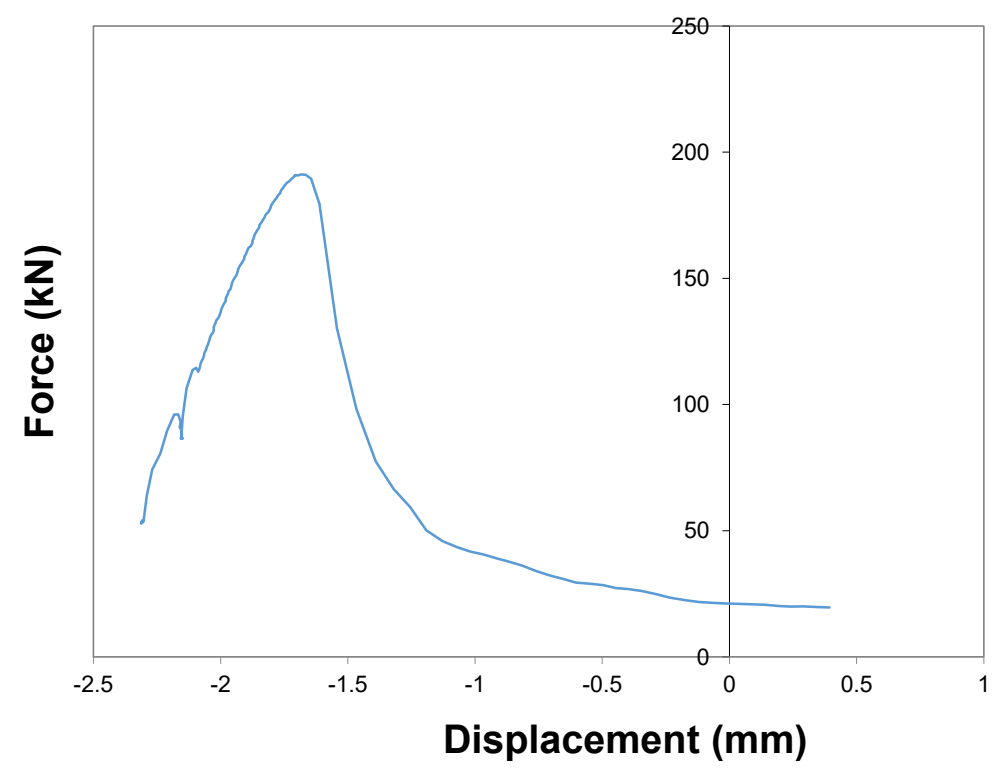

Figure 6. Force-displacement diagram.

The results obtained are compatible with the extent of the crack mapping process found in the pile cap investigated.

\subsection{Summary of ISR in Concrete Cores Dynamic Modulus Elasticity}

Three drilled concrete cores with the same size as those used for compression tests were tested and the results obtained were $26.19 \mathrm{GPa}, 1.71 \mathrm{GPa}$, and $17.70 \mathrm{MPa}$-with an 
average value of dynamic modulus of elasticity of approximately $21 \mathrm{GPa}$. This value is $26 \%$ higher than the static elastic modulus dynamic and it is consistent with previous research that stated that dynamic modulus of elasticity value of concrete is often higher than the static modulus of elasticity within a range of $20 \%$ to $40 \%$ [41]. Jalal [42] found, for undamaged concrete, values of dynamic modulus of elasticity of $38 \mathrm{GPa}$. If one compares these values, it is possible to conclude that ISR observed in concrete cores imposed a severe decrease in dynamic modulus of concrete (close to $-45 \%$ ). This fact represents the cracking process observed in the pile cap surface during the visual inspections and certifies the efficiency of this parameter as a good indicator of concrete damage due to ISRs [27,41-47].

\subsection{Gas Permeability}

Two samples were tested, and the values of permeability obtained were $1.3 \times 10^{-15} \mathrm{~m}^{2}$ and $3.9 \times 10^{-16} \mathrm{~m}^{2}$. These results show highlight the high permeability of the concrete. In fact, the usual values of this parameter for undamaged concrete are in the range of $10^{-18}-10^{-17} \mathrm{~m}[32,33]$. Values of porosity tests indicated $11.29 \%$ and $9.76 \%$ for the two concrete cores investigates, which are higher than those available in literature $[8,44]$.

The high values of the permeability coefficient obtained can explain the intense cracking process observed in the pile cap investigated and also suggests that it was the main factor responsible for the early deterioration process detected in the concrete elements investigated. Results obtained are consistent with previous research [4].

It is also important to highlight that the dynamic modulus of elasticity is influenced by the material porosity. As the concrete cores showed high porosity, this factor contributed significantly to the decrease of the dynamic modulus of the concrete. This fact can be explained by the strong network of cracks found in the cement paste due to the DEF mechanism that increases the density of the cracks in the samples.

\subsection{Scanning Electron Microscopy (SEM)}

In the analyses performed, specific parts that indicated the presence of delayed ettringite formation were chosen. The first one was the point \#305, where it can be seen that the morphology obtained highlighted the presence of aggregate particles with crystalline products. Figure 7 shows this part of the sample, with a magnitude of $234 \times$.

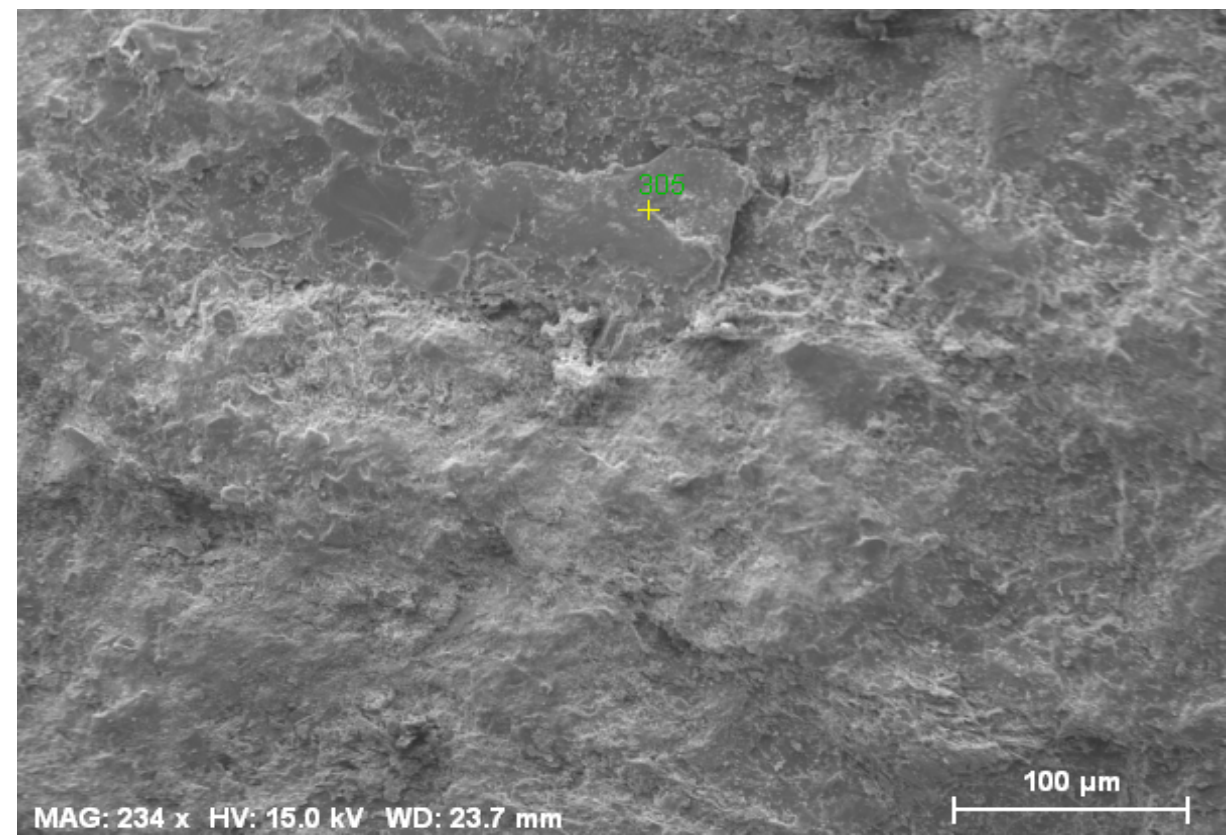

Figure 7. Aggregate particle with crystalline products from the ASR. 
The particle under analysis (see Figure 8) showed aluminium and silica in its chemical composition, indicating that components of delayed ettringite formation and crystalline products of alkaline reaction [12] acting together were observed.

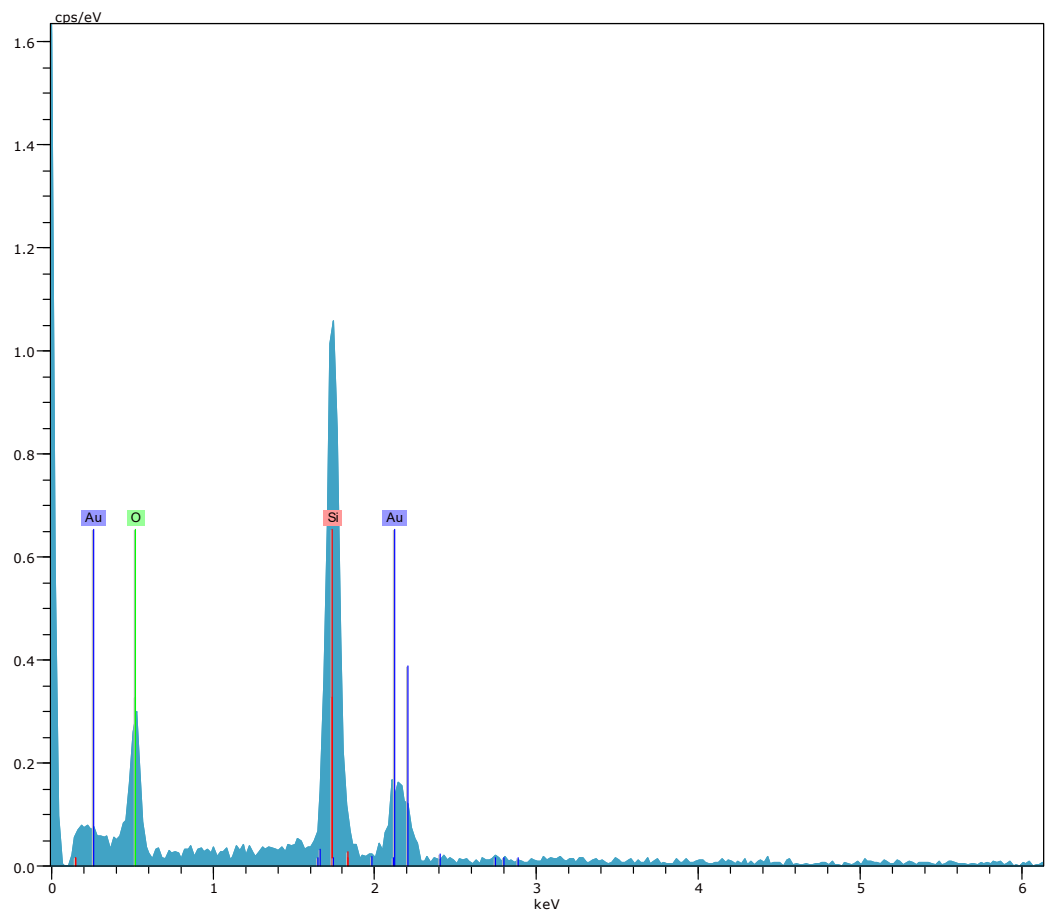

Figure 8. Crystalline product of alkali silica reaction (ASR).

At point 307 (see Figure 9), analysed by SEM, it is possible to observe ettringite developed crystals filling a pore whose corresponding chemical composition with the presence of Sulphur (S), Aluminium (Al), and Calcium (Ca) is showed in Figure 10. This aspect confirms the presence of a delayed ettringite, as well as Silicon ( $\mathrm{Si})$, indicating that crystalline elements of alkaline reaction [12] were found.

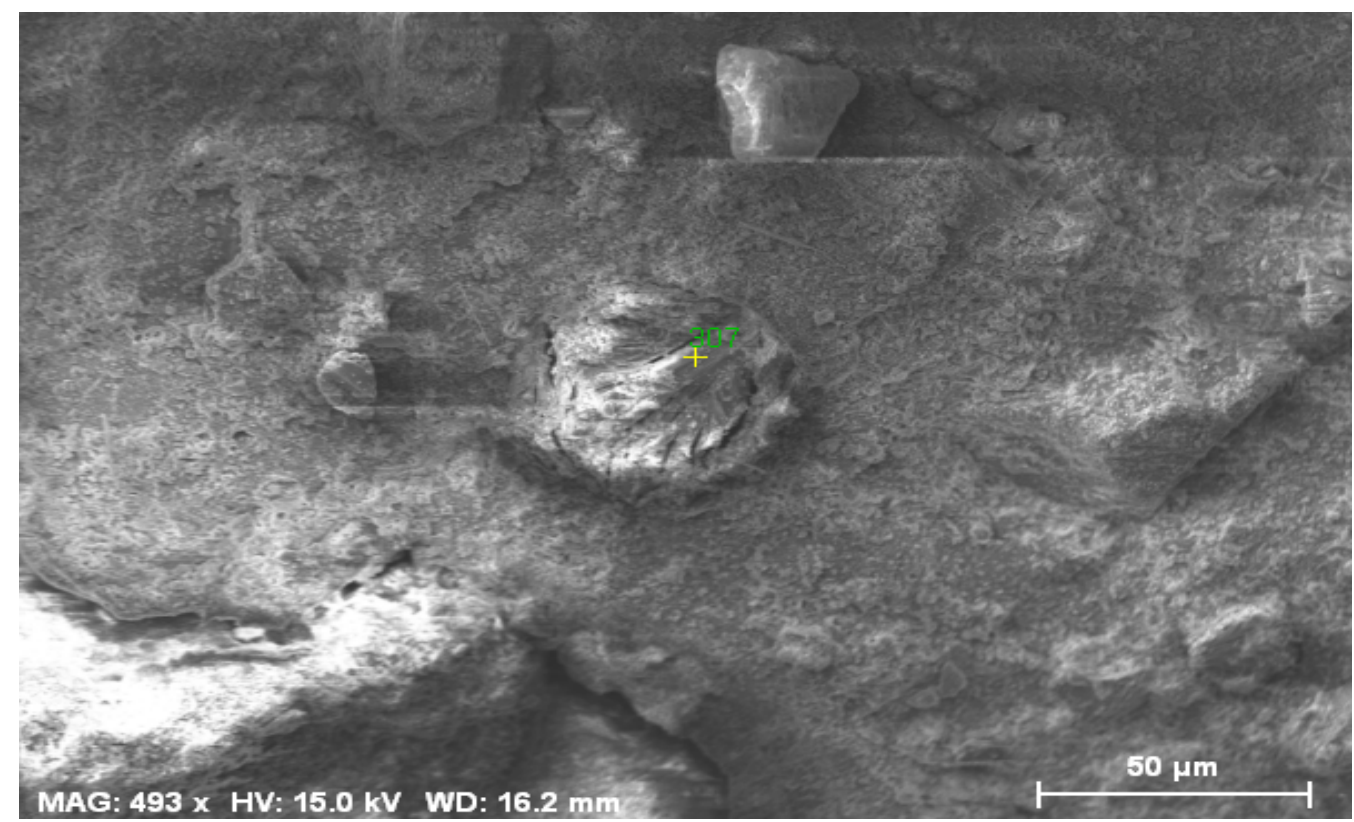

Figure 9. Ettringite crystals filling a pore. 


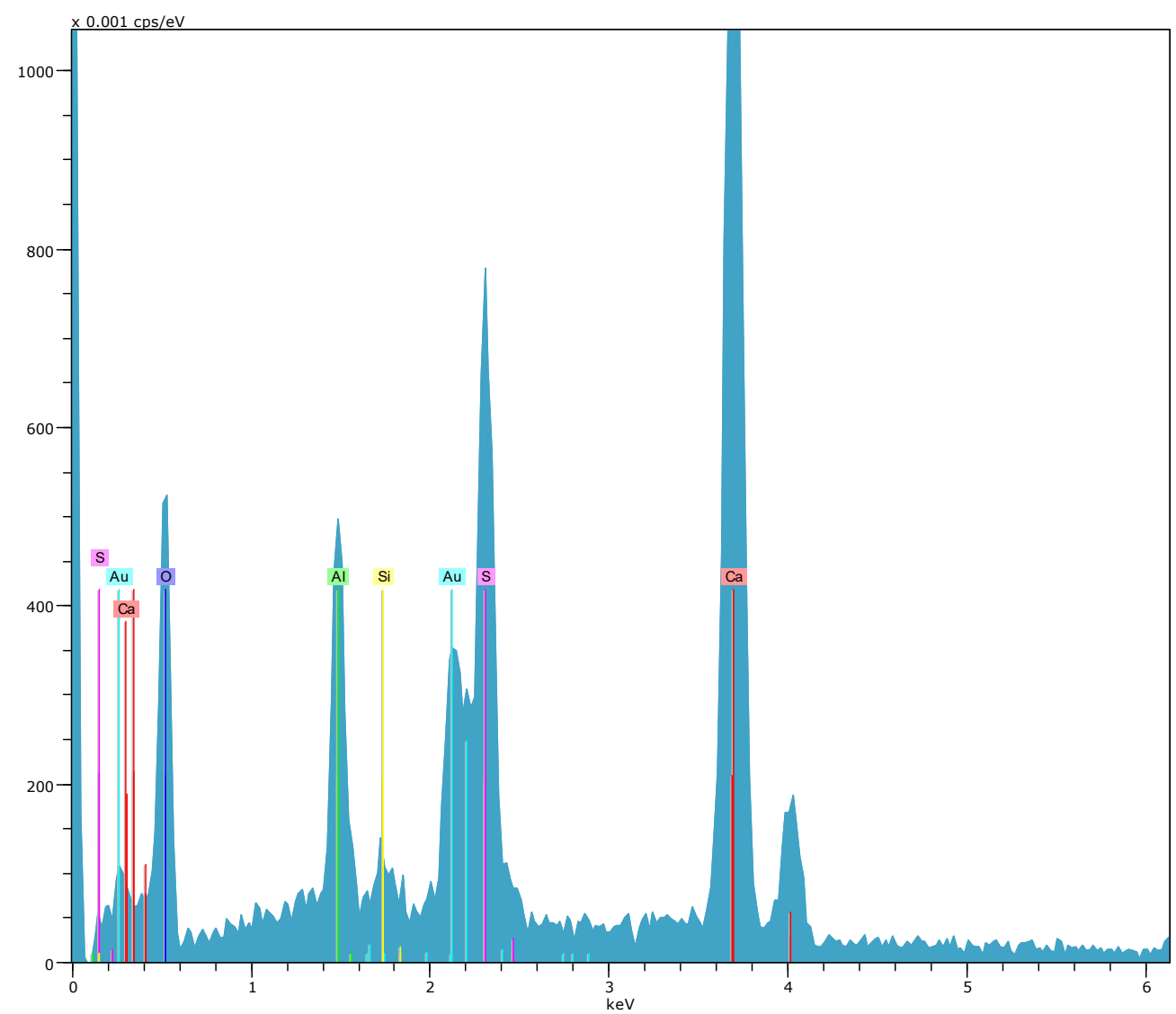

Figure 10. Chemical composition of the crystals.

\subsection{Pile Caps Repair and Rehabilitation Design}

The occurrence of internal expansion reactions in the pile cap investigated led to a decrease in the tensile strength of the concrete with a consequent weakening of the crack strength of the struts. As it was already reported by several researchers [48-50] cracks create preferential paths through which moisture and other aggressive agents can be transported into the concrete with great potential to amplify the damage caused by the internal swelling reaction. Taken into account this scenario, the retrofitting design process adopted two main hypotheses-a complete closure of all visible or not visible cracks and guarantee of the confinement of the most loaded piles in the cap.

In order to obtain information about the load capacity of each pile of the block investigated that allowed the decision about the best strategies to be adopted in the retrofitting design procedures, 3D-finite element linear static analyses were performed. C3D8R elements from ABAQUS [51] were used to generate the finite element meshes created to model the pile cap investigated. C3D8R is an eight-node general purpose linear brick element with reduced integration (1 integration point). In the modeling, the external planes of the columns cross sections and piles were kept rigid by imposing multiple point constraints. The ends of the piles were provided with springs to model piles with a length of $17 \mathrm{~m}$. Figure 11 shows the finite element model developed and the normal forces in the piles of the foundation block studied.

Stress resultants in the pile cap block, obtained from the finite element analysis for the most unfavorable design situation, were the following: Normal Force $(\mathrm{N})$ equal to $23,125 \mathrm{kN}$, Bending Moment over $x$ axis equal to $24,720 \mathrm{kNm}$, and Bending Moment over $y$ axis equal to $2390 \mathrm{kNm}$. For this load case, the maximum and minimum values of normal forces in the pile cap investigated are showed in Table 2. 

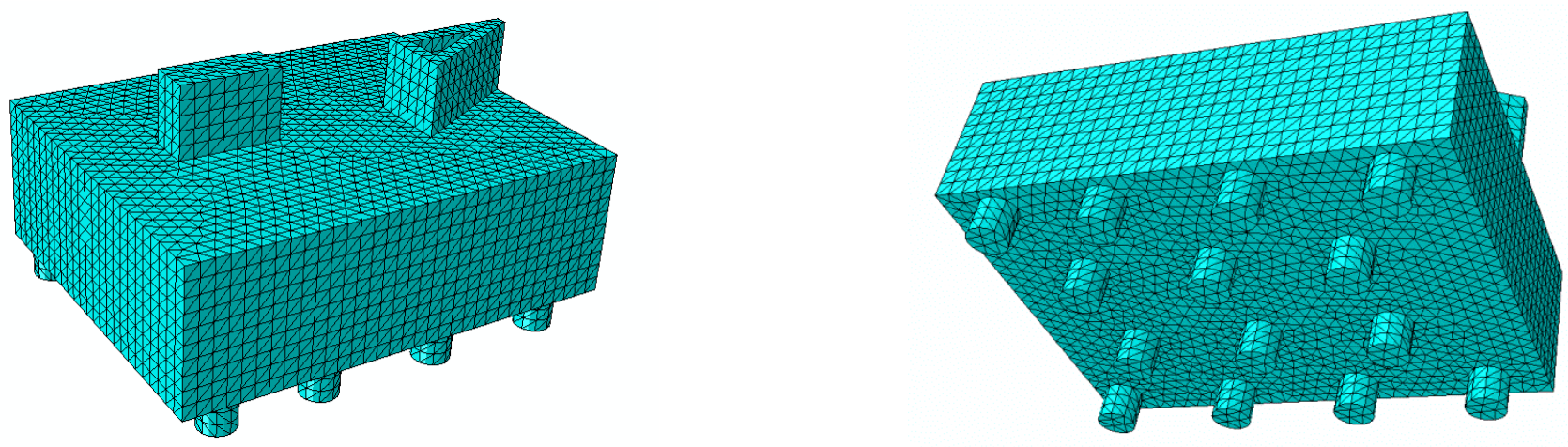

$R F, R F 3$

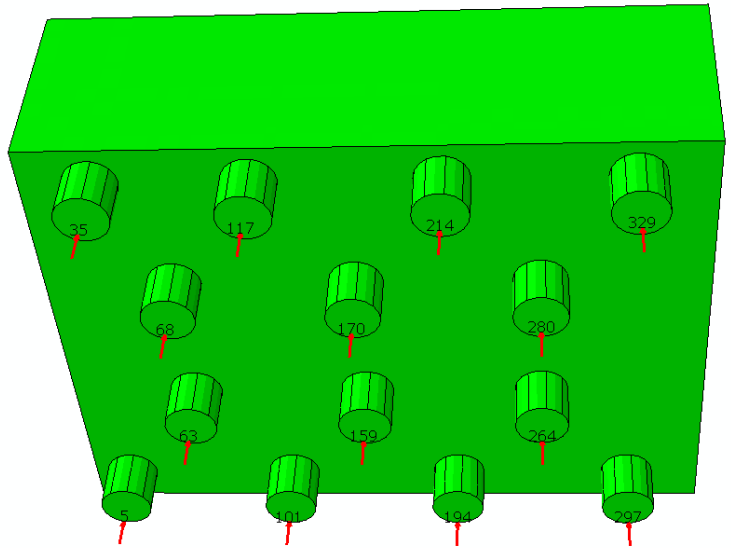

ODB: BlocoP6P9.odb Abacus/Standar
Yncrement 1: Step Time $=1.000$
Symbol Var: RF, RF3

Figure 11. Finite element model of the pile cap investigated and normal force in the piles.

Table 2. Maximum and minimum normal forces in the piles.

\begin{tabular}{cccc}
\hline \multirow{2}{*}{ Pile Cap Block } & Load Case & \multicolumn{2}{c}{ Pile Normal Force (kN) } \\
\cline { 2 - 4 } & Permanent & Maximum & Minimum \\
\hline \multirow{2}{*}{ B (P6 + P9) } & Permanent + Wind X $(+)$ & E2 $=1860$ & E1 = 1550 \\
\cline { 2 - 4 } & Permanent + Wind Y (+) & E2 $=3290$ & E13 = 1510 \\
\cline { 2 - 4 } & Permanent + Wind X $(-)$ & E13 $=1700$ \\
\cline { 2 - 4 } & Permanent + Wind $Y(-)$ & E13 $=3170$ & E2 $=1290$ \\
\hline
\end{tabular}

Stresses on the struts were calculated using ACI 318 [52] and the criterion of Adebar and Zhou [53], which is based on the value of contact stresses. The first two criteria are normative, while the third is a reference in the literature on the strut and tie model applied, specifically, to pile cap blocks. Table 3 shows the results of stress in struts, where it can be seen that the obtained values are higher than those foreseen in the ACI 318 [52] and Adebar and Zhou [53] approach, a situation that characterized an additional need to confine these piles in the block retrofitting design. In fact, the most loaded strut, corresponding to the pile \#1 in the block, presented a stress level that is approximately $70 \%$ higher than the limit allowed by the reinforced concrete design codes studied, for the most severe load case. 
Table 3. Stresses in struts.

\begin{tabular}{cccccc}
\hline \multirow{2}{*}{ Pile Cap Block } & \multirow{2}{*}{ Pile } & \multicolumn{5}{c}{ Strut Stress (MPa) } \\
\cline { 3 - 6 } & & ACI 318 [52] & Limit & Adebar and Zhou [53] & Limit \\
\hline \multirow{3}{*}{ B (P6 + P9) } & $\# 1$ & 25.3 & 15.5 & - & - \\
\cline { 2 - 6 } & $\# 13$ & 26.3 & 15.5 & - & - \\
\cline { 2 - 6 } & $\# 2$ & - & - & 19.8 & 19.5 \\
\hline
\end{tabular}

The strengthening design was developed to rehabilitate all the blocks of the foundation of the analyzed building. A special care was taken to assure enough confinement in the pile-block contact region at the bottom, mainly because the high stress levels in the piles and its location close to the corner of the pile cap block which are usually more vulnerable to displacements during the construction.

The mapping cracks observed on the surfaces of all blocks were injected with epoxy resin and the horizontal cracks of large opening were "stitched" with $\Phi=32 \mathrm{~mm}$ passive vertical reinforcement. The rehabilitation design aimed at providing a complete restoration of the structural integrity of the deteriorated element to make it monolithic as well as prevent addition expansion.

The main working hypothesis was formulated to assure physical restraint or containment with encapsulation of the affected member by a surrounding non-reactive concrete, applied stresses and supplementary use of active and passive reinforcement. Post-tensioning with $\Phi=32 \mathrm{~mm}$ Dywidag bars-ST 85/100 steel-was used in two directions. The bars were anchored in $16 \mathrm{~mm}$ steel plates placed on the pile cap lateral faces. Additional specific conditions were adopted in the rehabilitation project:

- Elimination of voids inside the pile cap block investigated with epoxy injection to restore the pre-cracking condition of the element;

- Restoration of the confinement and operation of the upper strut node in the region close to the column;

- Avoid moisture getting into the concrete element;

- Adoption of confinement of the lower region of the blocks to avoid pile cap interface failure;

- Guarantee of transmission of the horizontal shear from the block body to the upper layer sectioned by horizontal cracks;

- Installation of passive horizontal and vertical complementary reinforcement;

- Installation of active vertical reinforcement that is capable of ensuring the suspension of forces on the ties and the transmission of the horizontal shear, without the need for additional deformation of the existing reinforcement;

Details of the pile caps repair and rehabilitation design are shown in Figure 12. 

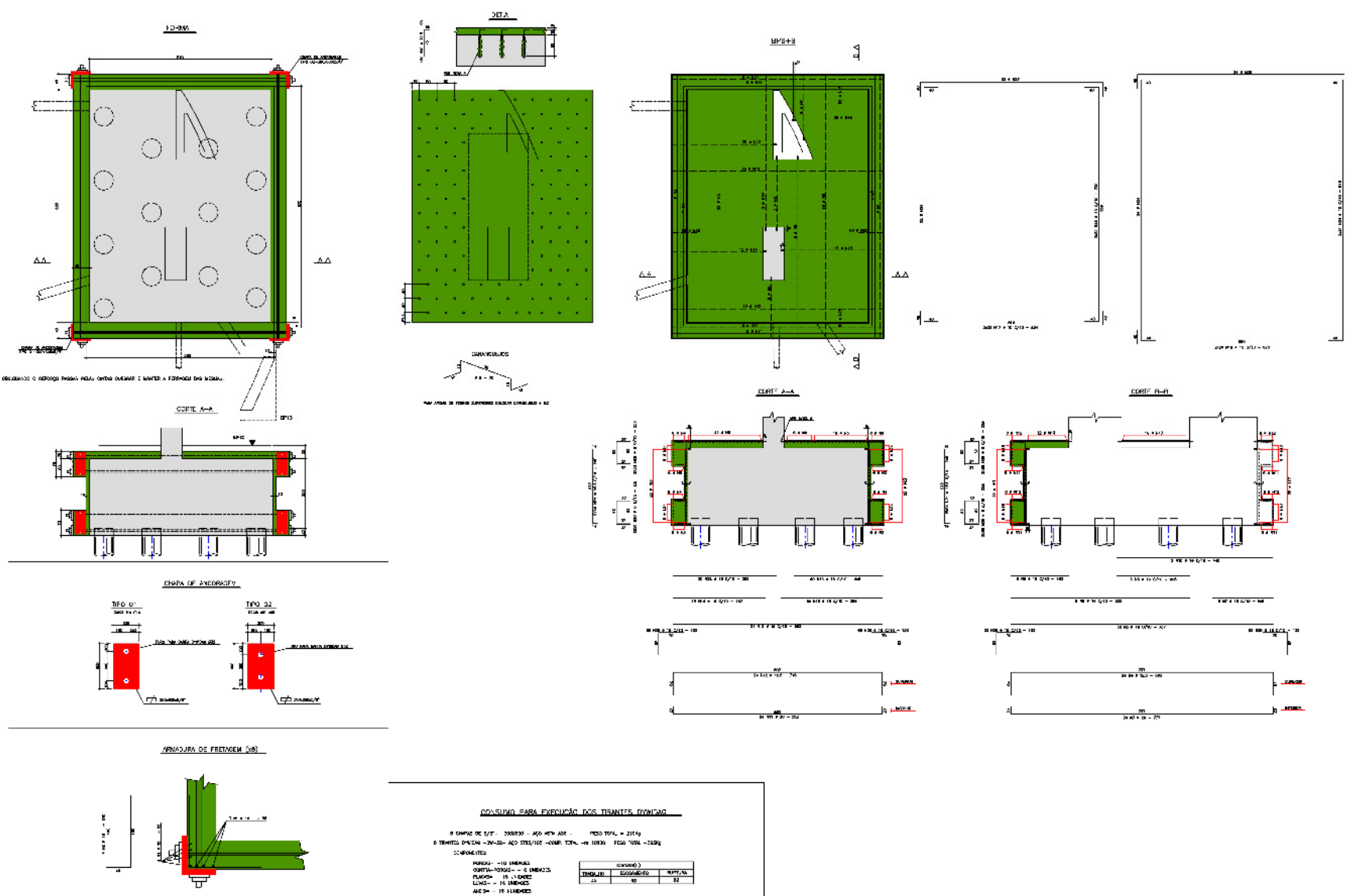

$\sqrt{\underbrace{n . . . m}_{n}}$
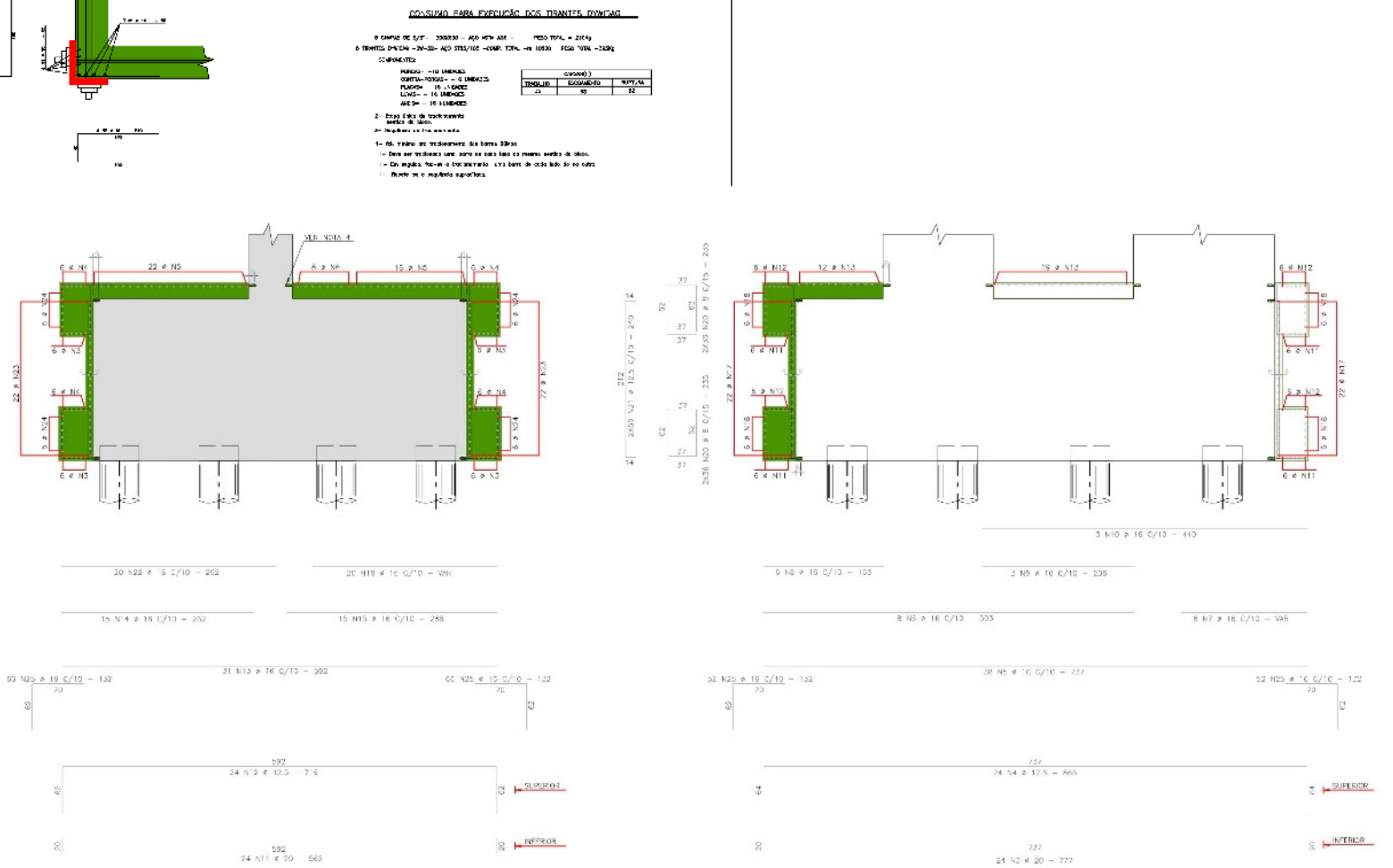

Figure 12. Strengthening design details of the pile cap investigated.

\section{Conclusions}

As a result of the intense cracking process observed in all the foundation pile caps of the building and based on all the physical-chemical tests performed on drilled concrete cores extracted, it can be stated that the concrete elements investigated presented chemical alterations that significantly affected the integrity and durability of the structure. Visual inspections indicated some alterations in a macroscopic level that were all confirmed during 
the microscopic investigations performed. Both ASR and DEF products were identified, the latter being the most frequent.

In addition to the general considerations listed above, it can be concluded from the various tests carried out that

- The compressive strength of concrete cores tested was not affected by concrete ISR, an aspect that corroborates results of previous research which states that the compressive strength is not a good indicator of the effect of ISR in concrete elements;

- Dynamic modulus of elasticity showed to be a good indicator of damage induced by ISR in the concrete element investigated;

- Rehabilitation procedures executed using strengthening procedures to provide the complete restoration of the structural integrity of the element deteriorated proved to be a good solution to retrofit pile cap deteriorated by expansions due to ISR of concrete.

Author Contributions: All the authors contributed to the development, analysis, writing, and revision of the paper: conceptualization, F.A.N.S., A.C.A. and J.M.P.Q.D.; methodology, F.A.N.S., T.M., A.K. and N.N.; validation, J.M.P.Q.D., A.C.A., N.N. and A.G.B.L.; formal analysis, A.C.A., J.M.P.Q.D. and A.G.B.L.; investigation, F.A.N.S., T.M., A.K. and N.N.; writing-original draft preparation, F.A.N.S., J.M.P.Q.D., A.C.A., N.N. and A.G.B.L.; writing-review and editing, F.A.N.S., J.M.P.Q.D., A.C.A., T.M., A.K., N.N. and A.G.B.L.; supervision, F.A.N.S., J.M.P.Q.D. and A.G.B.L. All authors have read and agreed to the published version of the manuscript.

Funding: This study was financed in part by the Coordenação de Aperfeiçoamento de Pessoal de Nível Superior-Brazil (CAPES) Finance Code 001.

Institutional Review Board Statement: Not applicable.

Informed Consent Statement: Not applicable.

Data Availability Statement: New data were created or analyzed in this study. Data will be shared upon request and consideration of the authors.

Acknowledgments: This study was supported by: Base Funding-UIDB/04708/2020 and Programmatic Funding-UIDP/04708/2020 of the CONSTRUCT-Instituto de I\&D em Estruturas e Construções-funded by national funds through the FCT/MCTES (PIDDAC).

Conflicts of Interest: The authors declare no conflict of interest.

\section{References}

1. Ferrotto, M.F.; Fischer, O.; Cavaleri, L. A strategy for the finite element modeling of FRP-confined concrete columns subjected to preload. Eng. Struct. 2018, 173, 1054-1067. [CrossRef]

2. Campione, G.; Cannella, F.; Cavaleri, L. Shear and flexural strength prediction of corroded R.C. beams. Constr. Build. Mater. 2017, 149, 395-405. [CrossRef]

3. Sanchez, L.F.M.; Drimalas, T.; Fournier, B.; Mitchell, D.; Bastien, J. Comprehensive damage assessment in concrete affected by different internal swelling reaction (ISR) mechanisms. Cem. Concr. Res. 2018, 107, 284-303. [CrossRef]

4. Collepardi, M. Damage by Delayed Ettringite Formation. Concr. Int. 1999, 21, 69-74.

5. Allard, A.; Bilodeau, S.; Pissot, F.; Fournier, B.; Bastien, J.; Bissonnette, B. Expansive behavior of thick concrete slabs affected by alkali-silica reaction (ASR). Constr. Build. Mater. 2018, 171, 421-436. [CrossRef]

6. Balachandran, C.; Muñoz, J.F.; Arnold, T. Characterization of alkali silica reaction gels using Raman spectroscopy. Cem. Concr. Res. 2017, 92, 66-74. [CrossRef]

7. Rajabipour, F.; Giannini, E.; Dunant, C.; Ideker, J.H.; Thomas, M.D.A. Alkali-silica reaction, Current understanding of the reaction mechanisms and the knowledge gaps. Cem. Concr. Res. 2015, 76, 130-146. [CrossRef]

8. Ghanem, H.; Zollinger, D.; Lytton, R. Predicting ASR aggregate reactivity in terms of its activation energy. Constr. Build. Mater. 2010, 24, 1101-1108. [CrossRef]

9. Mohammadi, A.; Ghiasvand, E.; Nili, M. Relation between mechanical properties of concrete and alkali-silica reaction (ASR) A review. Constr. Build. Mater. 2020, 258, 119567. [CrossRef]

10. Benmore, C.J.; Monteiro, P.J.M. The structure of alkali silicate gel by total scattering methods. Cem. Concr. Res. 2010, 40, 892-897. [CrossRef]

11. Carasek, H.; Hasparyk, N.P.; Melo, S.K.; Silva, H.H.A.B.; Martins, C. Influence of Hydration Heat on The Delayed Ettringite Formation (DEF) in Pozzolanic Portland Cement Concrete. In Proceedings of the 53rd Brazilian Congress of Concrete, Florianópolis-SC, Brazil, 1-4 November 2011. 
12. Hasparyk, N.P. Investigation of Concrete Affected by the Alkali-Aggregate Reaction and Advanced Characterization of Exudate Gel. Ph.D. Thesis, Federal University of Rio Grande do Sul, Porto Alegre, Brazil, 2005.

13. Shayan, A.; Al-Mahaidi, R.; Xu, A. Durability and Strength Assessment of AAR-Affected Bridge Deck Planks. In Proceedings of the 13th International Conference on Alkali-Aggregate Reaction in Concrete, Trondheim, Norway, 16-20 June 2008.

14. Li, S.; Deng, Z.; Li, C.; Chen, D.; Zhang, Y. Modeling of flexural strength degradation induced by alkali-silica Reaction. Constr. Build. Mater. 2020, 234, 117397. [CrossRef]

15. Kongshaug, S.S.; Oseland, O.; Kanstad, T.; Hendriks, M.A.N.; Rodum, E.; Markeset, G. Experimental investigation of ASR-affected concrete-The influence of uniaxial loading on the evolution of mechanical properties, expansion and damage indices. Constr. Build. Mater. 2020, 245, 118384. [CrossRef]

16. Mehta, P.K. Sulfate Attack on Concrete-A Critical Review. In Materials Science of Concrete III.; American Ceramic Society: Westerville, OH, USA, 1993; pp. 105-130.

17. Sanchez, L.F.M.; Fournier, B.; Mitchell, D.; Bastien, J. Condition assessment of an ASR-affected overpass after nearly 50 years in service. Constr. Build. Mater. 2020, 236, 117554. [CrossRef]

18. Kubo, Y.; Nakata, M. Effect of Reactive Aggregate on Mechanical Properties of Concrete Affected by Alkali-Silica Reaction. In Proceedings of the 14th International Conference on Alkali-Aggregate Reaction (ICAAR), Austin, TX, USA, $20-25$ May 2012.

19. Mehta, P.K.; Monteiro, P.J.M. Concrete: Microstructure, Properties and Materials, 4th ed.; McGraw-Hill Education: New York, NY, USA, 2014.

20. Taylor, H.F.W.; Famy, C.; Scrivener, K.L. Delayed ettringite formation. Cem. Concr. Res. 2001, 31, 683-693. [CrossRef]

21. ASTM E1876. Standard Test Method for Dynamic Young's Modulus, Shear Modulus, and Poisson's Ratio by Impulse Excitation of Vibration; ASTM International: West Conshohocken, PA, USA, 2015.

22. ASTM C215. Standard Test Method for Fundamental Transverse, Longitudinal, and Torsional Resonant Frequencies of Concrete Specimens; ASTM International: West Conshohocken, PA, USA, 2014.

23. BS EN 12504-4. Testing Concrete_Part 4, Determination of Ultrasonic Pulse Velocity; British Standard; British Standards Institution (BSI): London, UK, 2004.

24. Christaras, B.; Auger, F; Mosse, E. Determination of the moduli of elasticity of rocks. Comparison of the ultrasonic velocity and mechanical resonance frequency methods with direct static methods. Mater. Struct. 1994, 27, 222-228. [CrossRef]

25. Picandet, V. Influence of Mechanical Damage on The Permeability and Water Diffusivity of Concrete. Ph.D. Thesis, Nantes University, Nantes, France, 2001.

26. Malbois, M.; Nedjar, B.; Lavaud, S.; Rospars, C.; Divet, L.; Torrenti, J.M. On DEF expansion modelling in concrete structures under variable hydric conditions. Constr. Build. Mater. 2019, 207, 396-402. [CrossRef]

27. Picandet, V.; Khelidj, A.; Bastian, G. Effect of axial compressive damage on gas permeability of ordinary and high-performance concrete. Cem. Concr. Res. 2001, 31, 1525-1532. [CrossRef]

28. Choinska, M. Effects of Temperature, Mechanical State and Their Interactions on The Permeability of Structural Concrete. Ph.D. Thesis, Nantes University, Nantes, France, 2003.

29. Baroghel-Bouny, V. Microstructural and Water Characterization of Pasta of Cement and Ordinary and Very High Concrete Performances. Ph.D. Thesis, Paris University, Paris, France, 1994.

30. Saiyouri, N.; Bouasker, M.; Khelidj, A. Gas permeability measurement on injected soils with cement grout. Cem. Concr. Res. 2008, 38, 95-103. [CrossRef]

31. Martin, R.P.; Metalssi, O.O.; Toutlemonde, F. Importance of considering the coupling between transfer properties, alkali leaching and expansion in the modelling of concrete beams affected by internal swelling reactions. Constr. Build. Mater. 2013, 49, 23-30. [CrossRef]

32. Tahlaiti, M. Study of Chloride Penetration and Corrosion Initiation in Saturated and Tidal Zones. Ph.D. Thesis, La Rochelle University, La Rochelle, France, 2010.

33. Leemann, A. Raman microscopy of alkali-silica reaction (ASR) products formed in concrete. Cem. Concr. Res. 2017, 102, 41-47. [CrossRef]

34. Yu, X.T.; Chen, D.; Feng, J.R.; Zhang, Y. Behavior of mortar exposed to different exposure conditions of sulfate attack. Ocean Eng. 2018, 157, 1-12. [CrossRef]

35. Blight, G.E.; Alexander, M.G. Alkali-Aggregate Reaction and Structural Damage to Concrete, Engineering Assessment, Repair and Management; CRC Press: Boca Raton, FL, USA, 2011.

36. Martin, R.P. Experimental Analysis of The Mechanical Effects of Delayed Ettringite Formation on Concrete Structures. Ph.D. Thesis, Université Paris-Est., Champs-sur-Marne, France, 2010.

37. Martin, R.P.; Renaud, J.C.; Multon, S.; Toutlemonde, F. Structural Behavior of Plain and Reinforced Concrete Beams Affected by Combined AAR and DEF. In Proceedings of the 14th International Conference on Alkali Aggregate Reaction ICAAR14, Austin, TX, USA, 20-25 May 2012.

38. Noël, M.; Sanchez, L.; Tawil, D. Structural implications of internal swelling reactions in concrete, review and research needs. Mag. Concr. Res. 2018, 70, 1052-1063. [CrossRef]

39. Naar, R. Modélisation du Comportement Mécanique du Béton Par Approche Multi-Physique (Couplage Chimie-Mécanique), Application À la Réaction Alcali-Silice. Ph.D.Thesis, École Nationale Supérieure des Mines de Paris, Paris, France, 2009. 
40. Reinhardt, H.W.; Mielich, O. A fracture mechanics approach to the crack formation in alkali-sensitive grains. Cem. Concr. Res. 2011, 41, 255-262. [CrossRef]

41. Jiang, L.; Niu, D. Damage degradation law of concrete in sulfate solution and freeze-thaw environment. J. Cent. South. Uni. (Sci. Tech.) 2016, 47, 3208-3216. [CrossRef]

42. Jalal, M.; Grasley, Z.; Nassir, N.; Jalal, H. Strength and dynamic elasticity modulus of rubberized concrete designed with ANFIS modeling and ultrasonic technique. Constr. Build. Mater. 2020, 240, 117920. [CrossRef]

43. Zhang, D.; Mao, M.; Zhang, S.; Yang, Q. Influence of stress damage and high temperature on the freeze-thaw resistance of concrete with fly ash as fine aggregate. Constr. Build. Mater. 2019, 229, 116845. [CrossRef]

44. Guo, J.J.; Wang, K.; Guo, T.; Yang, Z.Y.; Zhang, P. Effect of dry-wet ratio on properties of concrete under sulfate attack. Materials 2019, 12, 2755. [CrossRef]

45. Gao, J.; Yu, Z.; Song, L.; Wang, T.; Wei, S. Durability of concrete exposed to sulfate attack under flexural loading and dryingwetting cycles. Constr. Build. Mater. 2013, 39, 33-38. [CrossRef]

46. Chen, F.; Qiao, P. Probabilistic damage modeling and service-life prediction of concrete under freeze-thaw action. Mater. Struct. 2015, 48, 2697-2711. [CrossRef]

47. Glasser, F.P.; Damidot, D.; Atkins, M. Phase development in cement in relation to the secondary ettringite problem. Adv. Cem. Res. 1995, 7, 57-68. [CrossRef]

48. Brown, M.D.; Sankovich, C.L.; Bayrak, O.; Jirsa, J.O.; Breen, J.E.; Wood, S.L. Design for Shear in Reinforced Concrete Using Strut-And-Tie Models; Report No. FHWA/TX-06/0-4371-2; University of Texas at Austin: Austin, TX, USA, 2006.

49. Farny, J.A.; Kerkhoff, B. Diagnosis and Control of Alkali-Aggregate Reactions in Concrete; Portland Cement Association: Skokie, IL, USA, 2007.

50. Sahmaran, M.; Li, V.C. Supressing alkali-silica expansion. ACI Concr. Int. 2016, 38, 47-52.

51. ABAQUS. ABAQUS Analysis User's Manual. Version 6.12; Dassault Systemes Simulia, Inc.: Johnstown, RI, USA, 2012.

52. ACI Committee. ACI-318 Building Code Requirements to Structural Concrete; Concrete Institute, ACI: Farmington Hills, MI, USA, 2014

53. Adebar, P.; Zhou, Z. Bearing strength of compressive struts confined by plain concrete. ACI Struct. J. 1993, 90, 534-541. 